\title{
Solar Biomass Pyrolysis with the Linear Mirror II
}

\author{
Hans Grassmann 1,2*, Marta Boaro3 ${ }^{3}$, Marco Citossi ${ }^{4}$, Marina Cobal $^{3}$, Enrico Ersettis ${ }^{2}$, \\ Elvis Kapllaj ${ }^{2}$, Andrea Pizzariello ${ }^{5}$ \\ ${ }^{1}$ Department of Civil Engineering and Architecture, University of Udine, Udine, Italy \\ ${ }^{2}$ Isomorph Production Srl, Gorizia, Italy \\ ${ }^{3}$ Department of Chemistry, Physics and Environment, University of Udine, Udine, Italy \\ ${ }^{4}$ Department of Electrical, Management and Mechanical Engineering, University of Udine, Udine, Italy \\ ${ }^{5}$ Department of Food Sciences, University of Udine, Udine, Italy \\ Email: hans.grassmann@uniud.it, marta.boaro@uniud.it, mcitossi@gmail.com, marina.cobal@cern.ch, \\ ersettis@isomorph.it, kapllaj@isomorph.it, andrea.pizzariello@uniud.it
}

Received 26 May 2015; accepted 11 July 2015; published 15 July 2015

Copyright (C) 2015 by authors and Scientific Research Publishing Inc.

This work is licensed under the Creative Commons Attribution International License (CC BY).

http://creativecommons.org/licenses/by/4.0/

C) (i) Open Access

\begin{abstract}
A simple and innovative prototype for biomass pyrolysis is presented, together with some experimental results. The setup uses only the thermal solar energy provided by a system of reflecting mirrors (Linear Mirror II) to heat a selected agro-waste biomass, such as wheat straw. At the end of the pyrolysis process, solar carbon with a high energy density (around $24-28 \mathrm{MJ} / \mathrm{kg}$ ) is produced from a biomass with an energy density of $16.9 \mathrm{MJ} / \mathrm{kg}$. The perspectives for a future industrial application of this setup are also discussed.
\end{abstract}

\section{Keywords}

Renewable Energy, Solar Biomass Conversion, Concentrated Solar Energy, Solar Pyrolysis, Linear Mirror

\section{Introduction: Biomasses and Pyrolysis}

Worldwide, there have been many studies to identify biomass sources and their amount, showing that there are at least several billion tons of biomass potentially available for conversion. In particular, agricultural crop residues, besides being used for animal feeding, can have a great potential as a raw under-used energy resource [1].

Historically, biomass has played a relevant role as a renewable energy source at low scale. On average, bio-

${ }^{*}$ Corresponding author.

How to cite this paper: Grassmann, H., Boaro, M., Citossi, M., Cobal, M., Ersettis, E., Kapllaj, E. and Pizzariello, A. (2015) Solar Biomass Pyrolysis with the Linear Mirror II. Smart Grid and Renewable Energy, 6, 179-186. 
mass contributes to less than $10 \%$ of the total energy supplies in industrialized countries, but only $3.0 \%$ to $3.5 \%$ of the yearly produced biomass is used in applications not related to foodstuff [2] [3].

Managing biomasses like herbaceous plants and grasses, which are bulky and moist (over 20\% - 50\% moisture depending on time left to dry) may imply high costs related to logistic aspects, such as drying, aggregating and transporting steps [4].

Unprocessed agricultural residues or woody wastes typically degrade over time due to natural deterioration since they are highly prone to decomposition and breakdown processes with exposure to moisture, pests, and other uncontrolled environmental conditions. One needs therefore a biomass pre-treatment, which can increase its energy density, slow down its biological degradation, and reduce its hydrophilicity. In recent years, several technologies of thermochemical biomass conversion have been developed, and gasification and pyrolysis have shown their capacity to recover the energy stored in plants by the photosynthetic process. These thermal processes provide an efficient, environmentally acceptable, and cost-effective method for the exploitation of a sustainable energy source [5] [6].

This paper concerns the pyrolysis of biomasses using uniquely solar thermal energy. Pyrolysis is a thermochemical, endothermic process, taking place under inert atmospheric conditions or in a limited supply of air. Among influential process parameters, the maximum temperature reached during the pyrolysis process is the most critical one to influence charcoal yields and properties. This temperature refers to the highest treatment temperature (HTT) for the raw feedstock during the process. Increasing HTT results in a progressive loss of hydrogen and oxygen and a concomitant enrichment in carbon [7]. The resultant C-rich charcoil is more resistant to microbial degradation as compared to fresh biomass. In addition, the pyrolysis process increases the calorific value and transforms the hygroscopic biomass into a hydrophobic material. In conventional pyrolysis, biomass is heated by burning fossil fuels, consuming part of the processed biomass or with the use of an electrical furnace. Alternatively, concentrated thermal solar energy can be used as heat source. Several are the advantages of a solar driven thermal carbonization: i) it delivers a higher carbonized material output per unit of feedstock because no portion of the feedstock is combusted for process heat; ii) the process is $\mathrm{CO}_{2}$ neutral and discharge of pollutants in the environment is avoided; iii) it offers an efficient way of chemically storing the intermittent solar energy in the form of a readily transportable fuel. A number of attempts to perform pyrolysis with solar energy based on different solar concentrating systems have been made [8].

In this paper, we present tests with a particularly simple solar concentrating device that has become available very recently, the Linear Mirror II [9]. The Linear Mirror has two particular advantages: 1) its construction is very simple, since its multiple reflecting surfaces are connected to each other by mechanical links, and operated all together by means of only three small motors; 2) the sunlight is concentrated on a target mounted in a fixed position which can be on the ground, unlike for instance the heat exchanger of a parabolic dish. This allows for a wide variety of different applications. The Linear Mirror II has a maximum thermal power of $9 \mathrm{~kW}$ and usually it is used to concentrate sunlight onto a suitable target. In this paper a device is described which uses the Linear Mirror II to perform straw pyrolysis only through solar energy and without any help from other thermal auxiliary sources.

\section{The Linear Mirror II and the Pyrolysis Device}

The Linear Mirror II has been developed by the academic spinoff Isomorph srl. As shown in Figure 1, it consists of an array of $4 \times 2$ mirrors, which follows the Zenith and the Azimuth positions of the Sun by means of three motors. Each of its eight mirrors consists of four segments with a slight relative inclination of $2^{\circ}$, resulting in a light concentration, which varies through the day, but is typically a factor of two.

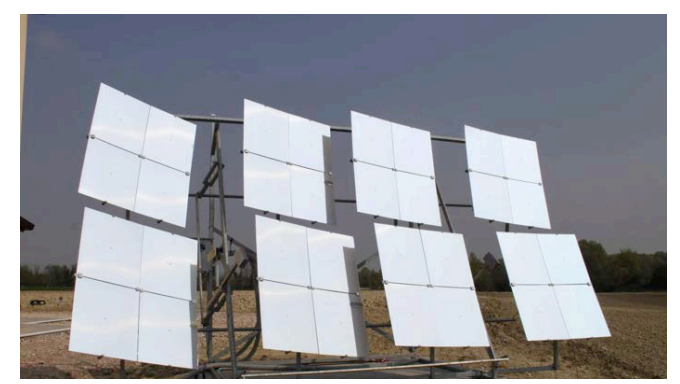

Figure 1. A Linear Mirror II device (without heat exchanger). 
A more detailed discussion of the Linear Mirror II principle of function can be found in [9]. The Linear Mirror II is now a regular industrial product, which has been tested and certified with the "Solar Keymark" certificate [10].

The tests were performed at the laboratory Eurofins, and the complete test report was made public at [11]. The schematic diagram of the pyrolysis setup (side and front view) is presented in Figure 2.

The device consists of a stainless steel retort $(100 \mathrm{~cm} \times 44 \mathrm{~cm} \times 46 \mathrm{~cm})$, which rotates around a horizontal axis at a speed of two rotations per minute. It can be considered a very simple version of a rotary kiln with manual material provision and extraction. The retort is heated by the Linear Mirror II. A secondary reflector is placed in the focal plane of the Linear Mirror II system and deflects the concentrated light (as shown in Figure 2, side view), so that the light enters the pyrolysis device from below. The retort is surrounded by a $10 \mathrm{~cm}$ thick mineral wool isolating cloth, which is open below, to let the sunlight enter. One side of the rotating axis of the retort consists of a steel tube, through which the pyrolysis gas and the water vapor leave. The retort is placed at a distance of $5 \mathrm{~m}$ in front of the mirror array in a fixed position. Two temperature sensors are used to monitor the device: one sensor is an infrared one measuring the temperature of the metal surface of the pyrolysis retort (sensor A) illuminated by the sunlight concentrated by the mirror. A second one (PT100) is mounted within the steel tube close to a face of the retort not illuminated, which will be colder (sensor B). The prototype concept is characterized by robustness, simplicity of operation, and a potential ability to accept bulky moist chopped organic feedstock.

Temperature measurements are presented for a run, which has been conducted in a sunny day. Figure 3 shows the time course of the temperatures measured by sensor A (green line) and B (red line).

Sensor A indicated that the operating temperature of $500^{\circ} \mathrm{C}$ was reached in about 90 minutes. Sensor B remained at ambient temperature during the first ten minutes of the experiment. After this time the sensor reached a steady state temperature of $300^{\circ} \mathrm{C}$ in about 100 minutes.

This heating process was accompanied by a strong production of fumes and gases, which stopped when sensor B had reached $300^{\circ} \mathrm{C}$. After 100 min the temperatures of sensors A and B were approximately constant indicating that the system had reached an operative thermal equilibrium. The slight decrease of about $50^{\circ} \mathrm{C}$ of the temperature measured by sensor A and B after 100 minutes can be attributed to the diminished solar intensity in the afternoon. After about 150 minutes the experiment was stopped by bringing the reflecting mirrors of the Linear Mirror II system into their park position. In correspondence a strong decrease of the temperature of sensor A can be seen.

A direct measurement of the temperature of the material was not performed: in order to get some a posteriori information on the temperature within the material and consequently on the nature of the material, its HHV has been compared to reference samples as described in Section 3.2.

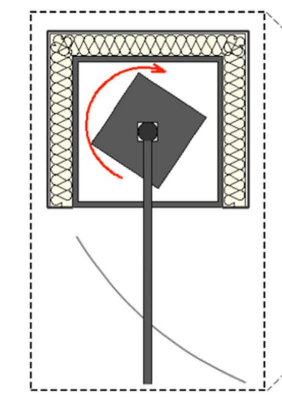

(a) (b)

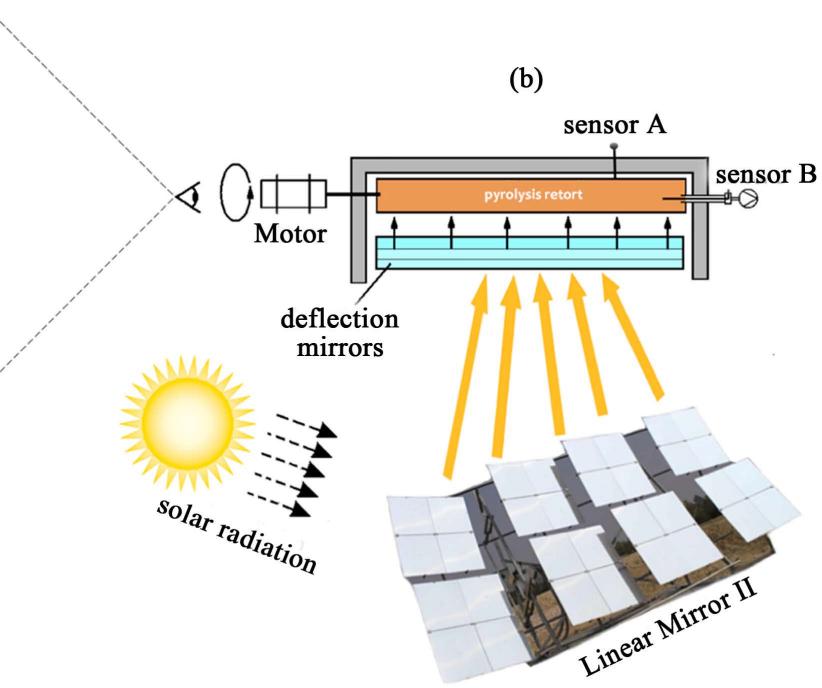

Figure 2. (a) Schematic side (left) view of the pyrolysis device, where the deflection mirrors under the retort are visible; (b) Drawing of the whole setup. 


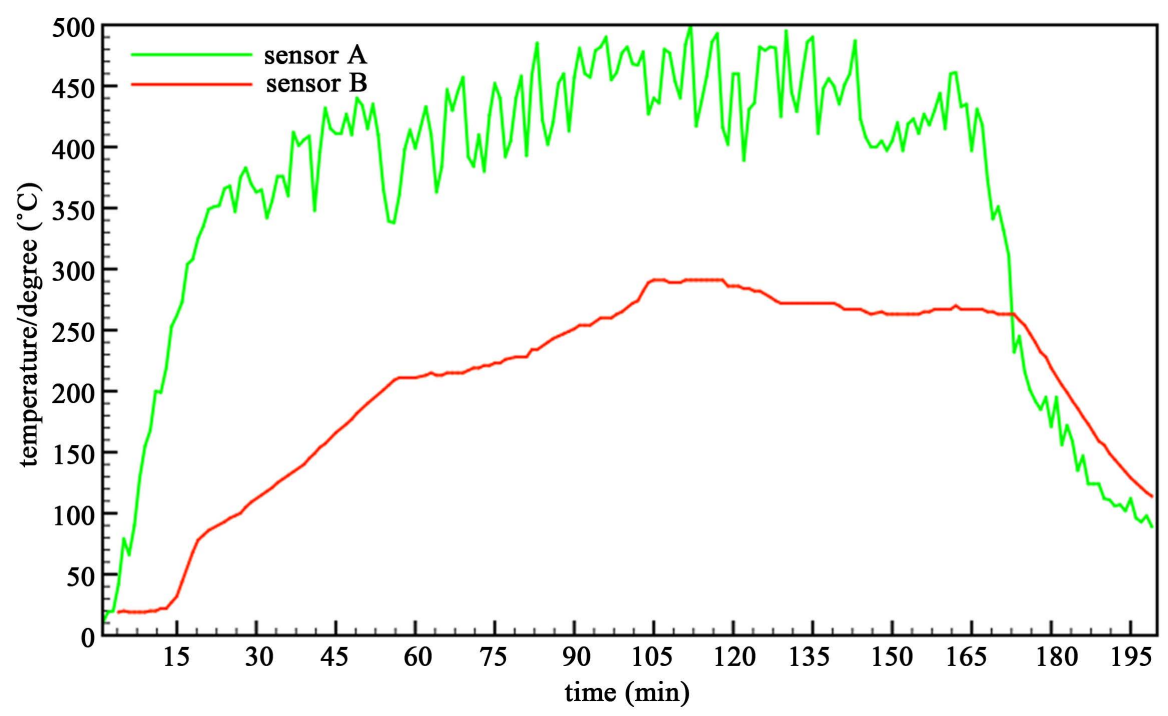

Figure 3. Temperature in ${ }^{\circ} \mathrm{C}$ of sensor A (measuring the temperature of the retort surface illuminated by the concentrated sunlight) and sensor B (within the steel tube close to a retort face not illuminated by the concentrated sunlight) as a function of time (in min).

\section{Performance of the Device}

The pyrolysis retort was filled with $5.0 \mathrm{~kg}$ of straw, and exposed to the concentrated sunlight, and was rotating at a speed of two rotations per minute. At the end of the process, the material inserted in the pyrolysis setup was reduced from an initial mass of $5.0 \mathrm{~kg}$ to $1.7 \mathrm{~kg}$ (which corresponds to a yield of about $36 \%$ ).

Since the pyrolysis process took 100 min of time, the device is able to process about $20 \mathrm{~kg}$ of straw in one day (8 hours), transforming it to $6.0 \mathrm{~kg}$ of solar carbon.

\section{Chemical Analysis of the Solar Carbon and Straw}

Chemical properties of straw and of the solar carbon produced were characterized through standard procedures.

\subsection{Biomass Sample Preparation and Characterization of Straw}

The feedstock used in this study was wheat straw provided by a local wheat farm located in Gorizia (Italy). The herbaceous biomass was ground and sieved to the particle size range $0.5-2.0 \mathrm{~mm}$. The particles were dried at $105^{\circ} \mathrm{C}$ for 8 hours before the experiment.

Thermogravimetric analyses of straw and charcoal were performed in a TGA 500TA instruments. TG analysis of the straw and of charcoal (solar carbon) was carried out in $\mathrm{N}_{2}$ and subsequently in air at a flow rate of 100 $\mathrm{cc} / \mathrm{min}$. All the analyses are characterized by an isothermal step at $150^{\circ} \mathrm{C}$ under $\mathrm{N}_{2}$ flow to quantify the initial moisture of specimens [12].

Figure 4 summarizes the TGA results related to the decomposition of straw in $\mathrm{N}_{2}$ and subsequently in air.

The first loss is associated to the amount of moisture in the straw, that is around $7 \mathrm{wt} \%$. The decomposition of straw in $\mathrm{N}_{2}$ increases rapidly from $170^{\circ} \mathrm{C}$ to $500^{\circ} \mathrm{C}$ registering the maximum rate at $325^{\circ} \mathrm{C}$. In this range the weight loss is almost of $70 \%$, then the process slows dramatically and at $900^{\circ} \mathrm{C}$ the total mass has been reduced of the $80 \%$. The $20 \%$ of mass left is constituted by a fraction of refractory carbon ( $13 \mathrm{wt} \%)$ and by ash ( 7 wt $\%)$.

The formation of refractory carbon at the end of the process is probably due to the partial condensation of lignin and cellulose to form graphitic structures [12]. The TG profile obtained is consistent with the thermal properties of the main constituents of straw, which are the hemicellulose, cellulose and the lignin [13]. The decomposition and volatilization of these substances occur at increasing temperature, being the lignin the most fire resistant component, followed by the cellulose and finally by the hemicellulose. This preliminary analysis indicates that an operating temperature of $500^{\circ} \mathrm{C}$ should have led to an almost complete pyrolysis of the wheatstraw. 


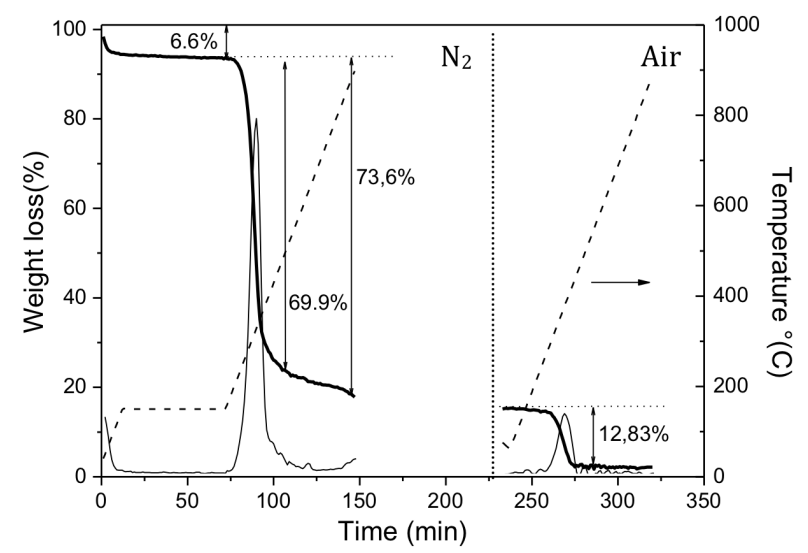

Figure 4. TG analysis of the wheat straw.

\subsection{Characterization of Solar Carbon}

The higher heating value (HHV) of the wheat straw and of the solar carbon were measured using a bomb calorimeter IKA C200 instrument with the DIN 51900-1 standard. The vessel was pressurized at 30 bar of oxygen. The uncertainty of the measurements is about $120 \mathrm{~J} / \mathrm{g}$. The high heating value (HHV) of solar charcoal ranges between 24.5 to $28.2 \mathrm{MJ} / \mathrm{kg}$ depending on the analyzed specimen, this variability could be due to an not homogeneous pyrolysis inside the retort, however the values measured are significant higher than that of straw 16.9 $\mathrm{MJ} / \mathrm{kg}$ and close to the HHV of fossil fuel.

For the sake of comparison, several samples of the same wheat straw, used also in the pyrolysis setup described here, have been heated at different temperatures in controlled conditions, using an oven for tests with a maximum operating temperature of $1050^{\circ} \mathrm{C}$ and isolation walls of high density ceramic fiber. The mass of the samples before and after heating, and therefore the residual mass in percentage have been measured, as shown in Table 1.

Raising the temperature, the residual mass percentage decreases as one would expect, and the higher heating value (HHV) increases. These values can be compared to the corresponding values obtained for the solar carbon in the pyrolysis experiment: this confirms that the temperature reached in the retort were between $350^{\circ} \mathrm{C}$ and $500^{\circ} \mathrm{C}$.

The chemical and physical properties of wheat straw and the solar charcoal are summarized in Table 2. The elemental analysis of straw and solar carbon was performed on a Vario EL Mod X (Vario Inc., USA).

Such analysis gives the weight percent of carbon, hydrogen, nitrogen, and sulfur in the samples simultaneously [14]. The oxygen content was estimated by mass difference, i.e. by subtracting from $100 \%$ the amount of $\mathrm{C}, \mathrm{H}, \mathrm{N}$ and ash [12].

Values measured are in agreement with those reported for straw-based bio-chars produced by conventional pyrolysis at $500^{\circ} \mathrm{C} \mathrm{[12]} \mathrm{[14].} \mathrm{The} \mathrm{hydrogen} \mathrm{to} \mathrm{carbon} \mathrm{ratio} \mathrm{is} \mathrm{also} \mathrm{consistent} \mathrm{with} \mathrm{that} \mathrm{of} \mathrm{other} \mathrm{chars.} \mathrm{However,}$ the $\mathrm{O} / \mathrm{C}$ molar ratio is slightly higher, probably owing to a non-complete decomposition of lignin, the most thermal resistant constituent of straw [15].

Scanning electron microscopy (SEM) images were obtained with a EVO-40 XPP (Zeiss) microscope equipped with an energy-dispersive X-ray detector (EDX), at 5 - $10 \mathrm{KV}$.

SEM images of solar charcoal (Figure 5) show that the structure of feedstock is still visible. The materials is characterized by oblong channels of $5-10 \mu \mathrm{m}$ of diameter and small pores $(2-3 \mu \mathrm{m})$ distributed throughout the surface.

On the base of the above results and on the categorization proposed by Keiluweit, Nico, Johnson and Kleber [16], we classified the charcoal obtained via solar pyrolysis as a mixture of transition and amorphous chars, in which the structure of straw is partially preserved and in part altered by the heating process.

Temperature programmed oxidation (TPO) was carried out over $4 \mathrm{mg}$ of solar carbon in a home-made equipment under $10 \mathrm{v} \% \mathrm{O}_{2}$ in $\mathrm{He}$ flow $(500 \mathrm{cc} / \mathrm{min})$ at a heating ramp of $10^{\circ} \mathrm{C} / \mathrm{min}$ up to $800^{\circ} \mathrm{C}$. The combustion products were monitored with a FT-IR multi gas analyser (Multi-Gas 2030, MKS Instruments).

The combustion of the solar charcoal was investigated with a temperature programmed oxidation (TPO) 


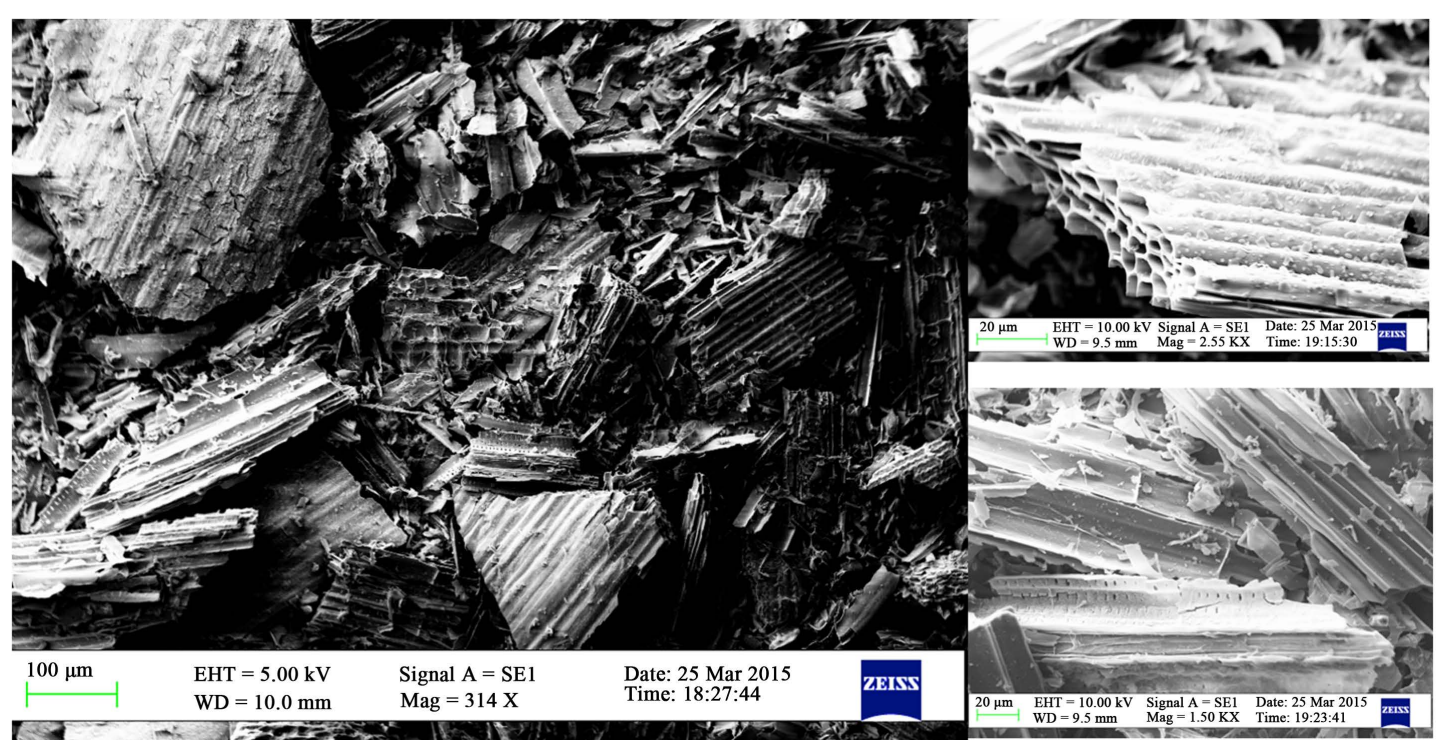

Figure 5. Micrographs of charcoal obtained from solar pyrolysis of wheat straw at $500^{\circ} \mathrm{C}$.

Table 1. Results from heating samples of wheat straw at different temperatures, in terms of residual mass in percentage and higher heating value (HHV).

\begin{tabular}{ccc}
\hline Temperature $\left({ }^{\circ} \mathrm{C}\right)$ & \% residual mass & HHV $(\mathrm{MJ} / \mathrm{kg})$ \\
\hline $300 \pm 10$ & $51.5 \pm 0.5$ & $22.6 \pm 0.1$ \\
$400 \pm 10$ & $39.6 \pm 0.4$ & $27.5 \pm 0.1$ \\
$500 \pm 10$ & $31.2 \pm 0.3$ & $28.5 \pm 0.1$ \\
\hline
\end{tabular}

Table 2. Characterization of wheat straw and charcoal obtained through solar pyrolysis with the Linear Mirror II. a.Average value estimated over three pyrolysis tests of measurements from different samples.

\begin{tabular}{ccc}
\hline Parameters (wt\%) & Wheat straw & Solar carbon \\
Carbon & $46 \pm 1$ & $70 \pm 1$ \\
Hydrogen & $6.0 \pm 0.1$ & $3.5 \pm 0.1$ \\
Nitrogen & $0.3 \pm 0.1$ & $0.8 \pm 0.1$ \\
Oxygen & $41 \pm 1$ & $0.4 \pm 0.1$ \\
Sulfur & $0.3 \pm 0.1$ & $10.5 \pm 0.1$ \\
Ash & $7.0 \pm 0.1$ & 0.2 \\
O/C (molar ratio) & 0.7 & 0.6 \\
H/C (molar ratio) & 1.6 & 0.1 \\
\hline
\end{tabular}

experiment in airflow. Figure 6 shows that the combustion of this material occurs in the range of $200^{\circ} \mathrm{C}-500^{\circ} \mathrm{C}$, producing mainly $\mathrm{CO}_{2}$, and $\mathrm{CO}$. The profile of combustion is complex with at least three components at $320^{\circ} \mathrm{C}$, $400^{\circ} \mathrm{C}$ and $450^{\circ} \mathrm{C}$. The component at lower temperature can be attributed to the combustion of volatile part of charcoal while the components at higher temperature are related to the combustion of non-volatile components (polyaromatics from lignin and refractory char formed during the process of pyrolysis)

TG analysis of solar charcoal in $\mathrm{N}_{2}$ (Figure 7) shows that at the end of the process the charcoal still contains $30 \mathrm{wt} \%$ of volatiles while the fixed carbon is of the order of $60 \mathrm{wt} \%$. Considering that at $500^{\circ} \mathrm{C}$ the thermal pyrolysis of straw led to an almost complete decomposition of it (see Figure 4), we inferred that the temperature 


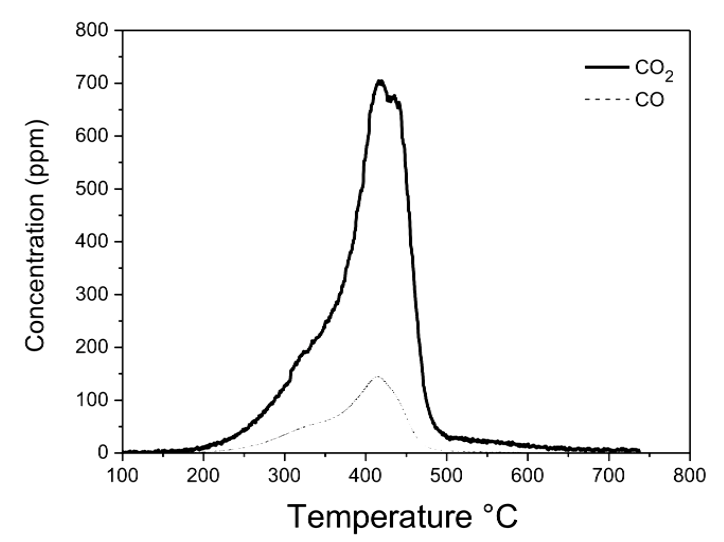

Figure 6. TPO profiles of the charcoal obtained via solar pyrolysis.

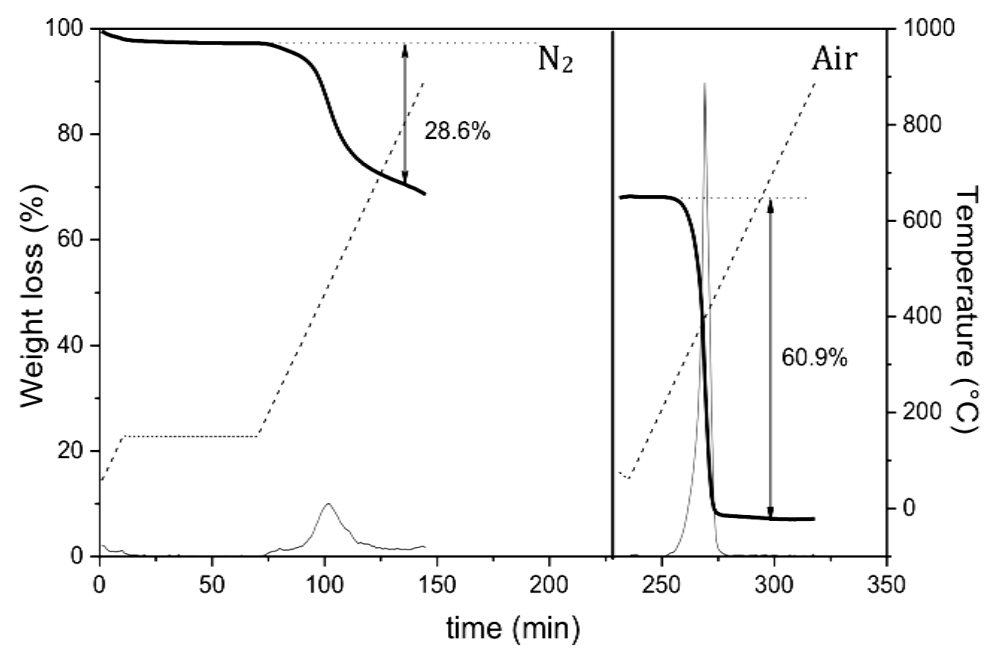

Figure 7. TG analysis of charcoal obtained via solar pyrolysis.

reached inside the pyrolyzer was on average lower than that measured at its outer walls. Such internal temperature was probably sufficiently high to decompose hemicellulose and cellulose, but only partially the lignin whose conversion to char requires temperature higher than $400^{\circ} \mathrm{C}$ [17]. On the other hand, the range of the measured HHV values suggests that an incomplete pyrolysis can be related to a non-homogeneous temperature inside the retort, despite temperature of $500^{\circ} \mathrm{C}$ can be reached. The result is indeed encouraging by keeping in mind that the system is a prototype and several improvements can be done to optimize the heat transfer from the outer walls to the inside of retort and homogenize the temperature of process.

\section{Conclusions}

The Linear Mirror II system has been successfully used to drive the pyrolysis of an agriculture biomass such as wheat straw using only the sunlight as source of heating.

The Linear Mirror II has been already used to heat water harvesting up to $50 \mathrm{kWh}$. The Linear Mirror II combined with a prototype rotatory kiln was able to transform $5 \mathrm{~kg}$ of straw in charcoal in about two hours. Assuming eight lighted hours of operation per day means a conversion of $20 \mathrm{~kg}$ of straw a day equivalent to $94 \mathrm{kWh}$ [17].

After the solar driven pyrolysis process most of this energy is found in the resulting carbon $-50 \mathrm{kWh}-$ the rest in the pyrolysis gases, i.e. in products with a higher energy density than the initial biomass. Carbon and gases can be stored for a long period of time and used as source of thermal energy at the occurrence. Solar pyrolysis of cheap biomass offers therefore an interesting combination of traditional solar thermal energy with biomass energy, which can help to substitute fossil fuels.

This substitution would not require new infrastructure or technologies especially if based in simple and scala- 
ble system such the Linear Mirror II. Further work is in progress to optimize the system and to make it an industrial product.

\section{Acknowledgements}

This work was in part sponsored by a grant from Camera di Commercio di Gorizia (Fondo Gorizia) and was supported by Area Science Park Trieste.

\section{References}

[1] Babu, B.V. (2008) Biomass Pyrolysis: A State-of-the-Art Review. Biofuels, Bioproducts and Biorefining, 2, 393-414. http://dx.doi.org/10.1002/bbb.92

[2] Grassmann, H., Chang, T.F.M., Taverna, M. and Iseppi, L. (2013) The Solar Age: Utopia and Dystopia. How to Transform Green Waste Esternalities in Energy and Biochar. Society, Integration, Education: Utopias and Dystopias in Landscape and Cultural Mosaic_-Visions Values Vulnerability, Udine, 3, 165-176.

Chang, T.F.M., Iseppi, L. and Grassmann, H. (2015) Transforming Vegetal and Animal Waste Flows and Stocks in Energy through Solar "Line-ar Mirror II", Accademia dei Lincei, Fondazione ENI-E. Matteri, La sfida dei Terawatt: quale ricerca per l'energia del futuro?, Rome.

[3] Montanarella, L. and Lugato, E. (2013) The Application of Biochar in the EU: Challenges and Opportunities. Agronomy, 3, 462-473. http://dx.doi.org/10.3390/agronomy3020462

[4] Verheijen, F.G.A., Jeffrey, S., Bastos, A.C., van der Velde, M. and Diafas, I. (2009) Biochar Application to Soils-A Critical Scientific Review of Effects on Soil Properties, P and Functions. EUR 24099 EN, Office for the Official Publications of the European Communities, Luxembourg, 149 p.

[5] Sohi, S.P., Krull, E., Lopez-Capel, E. and Bol, R. (2010) A Review of Biochar and Its Use and Function in Soil. Advances in Agronomy, 105, 47-82. http://dx.doi.org/10.1016/S0065-2113(10)05002-9

[6] Demirbas, A. (2001) Biomass Resource Facilities and Biomass Conversion Processing for Fuels and Chemicals. Energy Conversion and Management, 42, 1357-1378. http://dx.doi.org/10.1016/S0196-8904(00)00137-0

[7] Ateş, F. and Işıkdağ, M.A. (2008) Evaluation of the Role of the Pyrolysis Temperature in Straw Biomass Samples and Characterization of the Oils by GC/MS. Energy \& Fuels, 22, 1936-1943. http://dx.doi.org/10.1021/ef7006276

[8] Morales, S., Miranda, R., Bustos, D., Cazares, T. and Tran, H. (2014) Solar Biomass Pyrolysis for the Production of Bio-Fuels and Chemical Commodities. Journal of Analytical and Applied Pyrolysis, 109, 65-78. http://dx.doi.org/10.1016/j.jaap.2014.07.012

[9] Grassmann, H., et al. (2013) First Measurements with a Linear Mirror Device of Second Generation. Smart Grid and Renewable Energy, 4, 253-258. http://dx.doi.org/10.4236/sgre.2013.43030

[10] Solar Keymark (2013) http://www.estif.org/solarkeymarknew

[11] Report of Measurement According to EN 12975-2: 2006+A1:2010 (2010) Thermal Solar Systems and ComponentsSolar Collectors-Part 2: Test Methods. http://www.isomorph-production.it/images/TRIsomorph-rev-2.pdf

[12] Melo, L.C.A., Coscione, A.R., Abreu, C.A., Puga, A.P. and Camargo, O.A. (2013) Influence of Pyrolysis Temperature on Cadmium and Zinc Sorption Capacity of Sugar Cane Straw-Derived Biochar. BioResources, 8, 4992-5004. http://dx.doi.org/10.15376/biores.8.4.4992-5004

[13] Yang, Q. and Wu, S.B. (2009) Thermogravimetric Characteristics of Wheat Straw Lignin. Cellulose Chemistry and Technology, 43, 133-139.

[14] http://www.emme3-srl.it/wp-content/uploads/2015/03/1365413604BR_VarioELCube.pdf

[15] Jenkins, B.M., Baxter, L.L., Miles Jr., T.R. and Miles, T.R. (1998) Combustion Properties of Biomass. Fuel Processing Technology, 54, 17-46. http://dx.doi.org/10.1016/S0378-3820(97)00059-3

[16] Keiluweit, M., Nico, P.S., Johnson, M.G. and Kleber, M. (2010) Dynamic Molecular Structure of Plant Biomass-Derived Black Carbon (Biochar). Environmental Science \& Technology, 44, 1247-1253. http://dx.doi.org/10.1021/es9031419

[17] Jenkins, B. (1993) Properties of Biomass, Appendix to Biomass Energy Fundamentals, EPRI Report TR-102017, January, 1993. http://cta.ornl.gov/bedb/appendix_a/Heat_Content_Ranges_for_Various_Biomass_Fuels.xls 